\title{
CARACTERIZACIÓN DE LA DIVERSIDAD GENÉTICA DE CULTIVARES COMERCIALES DE HELICONIAS EN EL CENTRO OCCIDENTE DE COLOMBIA
}

\author{
Marta Leonor Marulanda*, Liliana Isaza ${ }^{1 / *}$, Paola Andrea López* \\ Palabras clave: Microsatélites; transferibilidad; identificación varietal; SSR. \\ Keywords: Microsatellites; transferability; varietal identification; SSR. \\ Recibido: $15 / 02 / 17$ \\ Aceptado: 04/08/17
}

RESUMEN

La familia Heliconiaceae tiene un solo género, Heliconia L., con aproximadamente 250 especies. Debido al colorido de sus brácteas son muy usadas para fines ornamentales presentando una creciente comercialización en el mercado internacional, lo que ha incentivado el aumento en el área productiva en los países de Centro y Sur América, al proporcionar una mayor oferta y demanda del producto. Sin embargo, existe en este género, confusión sobre el número de especies y las relaciones entre ellas. Esta inapropiada nomenclatura, puede originar problemas a nivel comercial y científico. En esta investigación realizada durante el 2014, se caracterizaron genéticamente 44 individuos del género Heliconia de importancia comercial en el centro occidente de Colombia, que corresponden a 4 especies, y un híbrido interespecífico, por medio de la amplificación de marcadores microsatélites previamente desarrollados para Heliconia bihai y Heliconia caribaea y marcadores microsatélites propios obtenidos del desarrollo de una librería genómica enriquecida con microsatélites para Heliconia orthotricha. Se seleccionaron 18 marcadores para realizar las caracterizaciones. Se utilizaron

1 Autora para correspondencia. Correo electrónico: ubioteve@utp.edu.co

\section{ABSTRACT}

\begin{abstract}
Characterization of the genetic diversity of commercial cultivars of heliconias in The Central Occident of Colombia. The Heliconiaceae family has only one genus, Heliconia L., with approximately 250 species. Due to the color of their bracts, they are widely used for ornamental purposes, presenting an increasing commercialization in the international market, and the production areas in Central and South America countries, providing a greater supply and demand of the product. However, there is confusion in this genus about the number of species and the relationships between them. This improper nomenclature can lead to commercial and scientific problems. In this research carried out during 2014, 44 individuals of the genus Heliconia of commercial importance in central west of Colombia, corresponding to 4 species, and an interspecific hybrid, were characterized by microsatellite markers previously developed for Heliconia bihai and Heliconia caribaea and own microsatellite markers obtained from a genomic enriched library with microsatellites for Heliconia orthotricha. Eighteen markers were selected to perform the characterizations. Direct
\end{abstract}

\footnotetext{
* Universidad Tecnológica de Pereira, Facultad de Ciencias Ambientales. Laboratorio de Biotecnología Vegetal, Pereira, Colombia.
} 
las estrategias de amplificación directa, así como la transferibilidad de marcadores. El equilibrio Hardy-Weinberg (EHW) se rompió para algunos de los marcadores empleados en las diferentes especies de este estudio, ya que pertenecían a cultivares comerciales con alta presión de selección por parte de los cultivadores. El marcador Hb_C115 presentó el ligamiento con un mayor número de marcadores. Muchos de los marcadores están ligados entre sí y al no poseer mapas de ligamiento para ninguna especie del género no es posible determinar la cercanía de los mismos en los cromosomas. Se confirma la transferibilidad de los microsatélites desarrollados para diferentes especies del género Heliconia, como una herramienta útil en la caracterización varietal, la cual podría ser de gran uso en la comercialización de flores e intercambio de material vegetal para propagación asexual.

\section{INTRODUCCIÓN}

La familia Heliconiaceae tiene un solo género, Heliconia L., con aproximadamente 200 a 250 especies. Debido al colorido de sus brácteas son muy usadas para fines ornamentales (Andersson 1998). Recientemente, se ha presentado una creciente comercialización en el mercado internacional, lo que ha incentivado el aumento en el área de producción en los países de América Central y de América del Sur, lo cual proporciona una mayor oferta y demanda del producto. Tradicionalmente, el mejoramiento de especies de interés comercial se ha realizado mediante la selección sobre la base del fenotipo, sin embargo, la influencia del ambiente puede en alguna medida afectar la expresión genética de las plantas.

$\mathrm{El}$ género Heliconia L. contiene una gran diversidad de especies, variedades, híbridos y cultivares de interés ornamental y comercial. Sin embargo, existe en este género incertidumbre sobre el número de especies y las relaciones entre ellas (Marouelli et al. 2010). La gran diversidad amplification strategies were used, as well as the transferability of markers. The Hardy-Weinberg equilibrium (HWE) was broken for some of the markers used in the different species of this study, because they belonged to commercial cultivars with high selection pressure by growers. The marker Hb_C115 presented the linkage with a greater number of markers. Many of the markers are linked to each other, it is not possible to determine their proximity to the chromosome, because they do not have linkage maps for any species of the genus. The transferability of the microsatellites developed for different species of the genus Heliconia is confirmed as a useful tool in the varietal characterization, which could be of great use in the commercialization of flowers and exchange of plant material for asexual propagation.

de especies, cultivares e híbridos ha permitido el uso de sinónimos; esta inapropiada nomenclatura se debe frecuentemente a una identificación incorrecta, que puede originar problemas tanto a nivel comercial como científico (Castro et al. 2007).

Los descriptores morfológicos se han utilizado frecuentemente para la determinación de la diversidad fenotípica y para la diferenciación de algunos cultivares del género Heliconia e híbridos interespecíficos (Berry y Kress 1991, Loges et al. 2007, Costa et al. 2009, Guimarães et al. 2014). Estos descriptores son usualmente multicategóricos y cualitativos, y están relacionados con las funciones estructurales de las plantas y sus características morfológicas, algunos descriptores son binarios cuando se refieren a presencia o ausencia de cierta característica (Guimarães et al. 2014). Por lo tanto, los estudios moleculares pueden ayudar a determinar la variabilidad genética en el género y su proceso de especiación.

En heliconias, para identificar a qué especie o híbrido pertenece un rizoma, es necesario 
esperar la emisión de la inflorescencia para hacer un análisis del fenotipo resultante. Es por esto que el uso de las técnicas moleculares permite la estimación de la diversidad genética dentro y entre especies, para estudios poblacionales, clasificación de germoplasma, mejoramiento e identificación de genes, de caracteres cualitativos y cuantitativos mediante la identificación del polimorfismo directamente del ADN (Cornide 2000). En esta investigación se plantearon como objetivos caracterizar la diversidad genética e identificar cultivares comerciales del género Heliconia de importancia comercial en el centro occidente de Colombia con marcadores microsatélites, teniendo en cuenta que Colombia es el segundo productor de flores mundial después de Holanda (UN Comtrade 2014). Para realizar la caracterización de las especies antes mencionadas, se utilizaron microsatélites desarrollados por Gowda et al. (2012) para las especies Heliconia bihai (Microsatélites $\mathrm{Hb}$ ) y Heliconia caribaea (Microsatélites Hc) y las parejas de primers obtenidas a partir del desarrollo de una librería genómica propia, de la especie Heliconia orthotricha cv. Tricolor (Microsatélites Ho), desarrollada previamente.

\section{MATERIALES Y MÉTODOS}

Material vegetal: Durante el 2014, se seleccionaron 44 individuos pertenecientes a 4 especies e híbridos interespecíficos del género Heliconia (Cuadro 1), cultivados por productores de flores, en la zona centro - occidente de Colombia. En la Figura 1 se presentan algunos ejemplares de las muestras seleccionadas.

Cuadro 1. Muestras de cultivares comerciales del género Heliconia.

\begin{tabular}{clc}
\hline Código de la muestra & Especie/Híbrido & $\begin{array}{c}\text { Número de cultivares } \\
\text { comerciales analizados }\end{array}$ \\
\hline $\mathrm{Hb}$ & Heliconia bihai & 11 \\
$\mathrm{Hc}$ & Heliconia caribaea & 8 \\
$\mathrm{HcxHb}$ & H. caribaea H. bihai & 4 \\
$\mathrm{Ho}$ & H. orthotricha & 11 \\
$\mathrm{Hs}$ & H. stricta & 10 \\
\hline
\end{tabular}



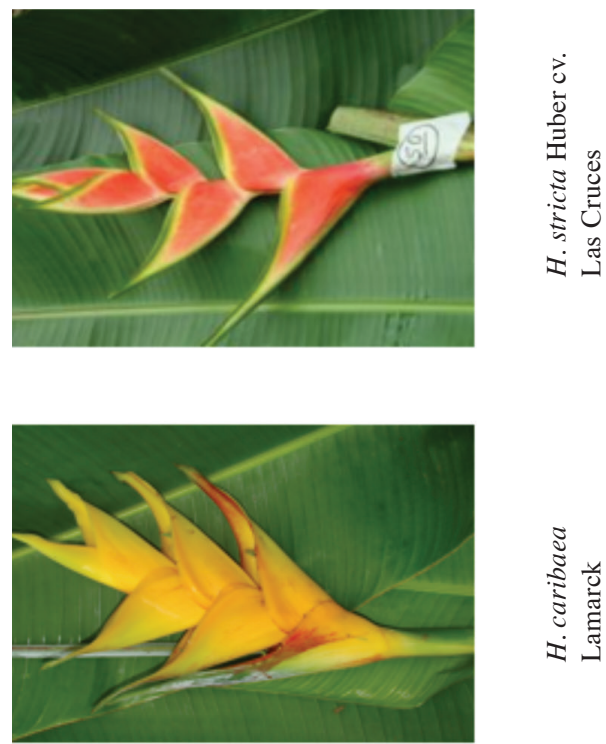

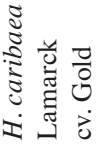
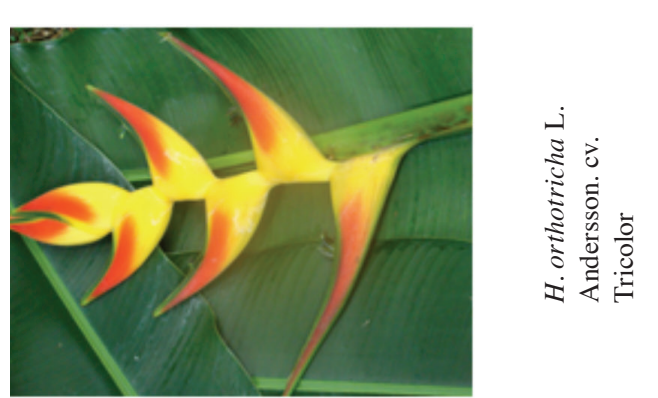

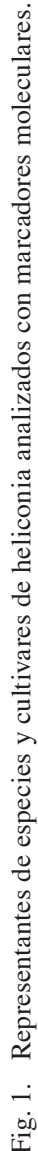

Agronomía Costarricense 42(1): 7-20. ISSN:0377-9424 / 2018 
Extracción de ADN: La extracción del ADN se realizó a partir de tejido foliar, el cual se almacenó en gel de sílice granulado, sin cobalto, proporción 1:10 (1 gramo de tejido vegetal por 10 gramos de gel de sílice) en bolsas plásticas con cierres herméticos. Como método de extracción se empleó el descrito por Sheela et al. (2006); donde a la muestra foliar se le añadieron $2,5 \mathrm{ml}$ de CTAB al $2 \%$ y $300 \mu \mathrm{l}$ de polivinilpirrolidona (PVP) al 1\%. A los contenidos se agregaron $5 \mathrm{ml}$ de tampón de extracción CTAB [2\% (p / v) de CTAB, 100 mM Tris HCL (pH 8,0), $\mathrm{NaCl} 1,4 \mathrm{M}$, EDTA $20 \mathrm{mM}, 0,2 \%$ de mercaptoetanol]. Posteriormente, se añadió 1 $\mathrm{ml}$ de solución de PVP (1\%) y se incubó a $60^{\circ} \mathrm{C}$ durante 30 minutos. Se adicionó un volumen igual de fenol: cloroformo: alcohol isoamílico (25: 24: 1), luego se centrifugó a $15000 \mathrm{rpm}$ durante 10 minutos a $5^{\circ} \mathrm{C}$. La fase superior se recuperó con cloroformo: alcohol isoamílico (24: 1), 0,1 volumen de acetato de sodio $3 \mathrm{M}$ ( $\mathrm{pH} 4,8)$ y $2 / 3$ de volumen de isopropanol, luego se llevó a centrifugación a $10000 \mathrm{rpm}$ por 5 minutos a $5^{\circ} \mathrm{C}$. El sobrenadante se decantó cuidadosamente y el sedimento de ADN se lavó con etanol frío al 70\%. El precipitado de ADN se disolvió en $100 \mu \mathrm{l}$ de TE (Tris $\mathrm{HCl} 10 \mathrm{mM}$, EDTA $1 \mathrm{mM}, \mathrm{pH} 8,0$ ) y fue almacenado a $4^{\circ} \mathrm{C}$, para mejorar la calidad del ADN, se realizó una purificación con el protocolo descrito por Castillo (2006).
Caracterización de las muestras con marcadores microsatélites (SSR): La caracterización de la diversidad genética de las especies del género Heliconia; se realizó a partir de los primers desarrollados por Gowda et al. (2012) para Heliconia bihai (SSR Hb) y Heliconia caribaea (SSR Hc) y las parejas de primers obtenidas a partir del desarrollo de una librería genómica propia de la especie Heliconia orthotricha cv. Tricolor (SSR Ho) construida previamente (secuencias depositadas por los autores en el NCBI, por sus siglas en inglés National Center for Biotechnology Information). En total, se evaluaron 18 parejas de primers (Cuadro 2). Las reacciones de amplificación se hicieron en un volumen final de $10 \mu \mathrm{l}$ con $0,3 \mu \mathrm{M}$ de cada uno de los primers, $15 \mu \mathrm{M}$ de cada DNTP, $1 \mathrm{X}$ de buffer de reacción $(10 \mathrm{mM}$ de Tris $\mathrm{HCl}, 50 \mathrm{mM}$ de $\mathrm{KCl}$ ), $1 \mathrm{U}$ de Taq polimerasa, $2 \mathrm{mM}$ de $\mathrm{MgCl}_{2}$ y $10 \mathrm{ng} . \mu \mathrm{L}^{-1}$ de ADN. El perfil de amplificación fue $94^{\circ} \mathrm{C} 5$ minutos desnaturalización inicial, 35 ciclos de $94^{\circ} \mathrm{C}$ un minuto, temperatura de apareamiento estandarizada para cada pareja de primers (Cuadro 2) un minuto y $72^{\circ} \mathrm{C}$ un minuto y una extensión final de $72^{\circ} \mathrm{C} 10$ minutos. La separación de los productos amplificados se realizó mediante electroforesis en geles desnaturalizantes de poliacrilamida al 6\%. Los geles fueron teñidos con nitrato de plata y se siguió el protocolo de Benbouza et al. (2006). 


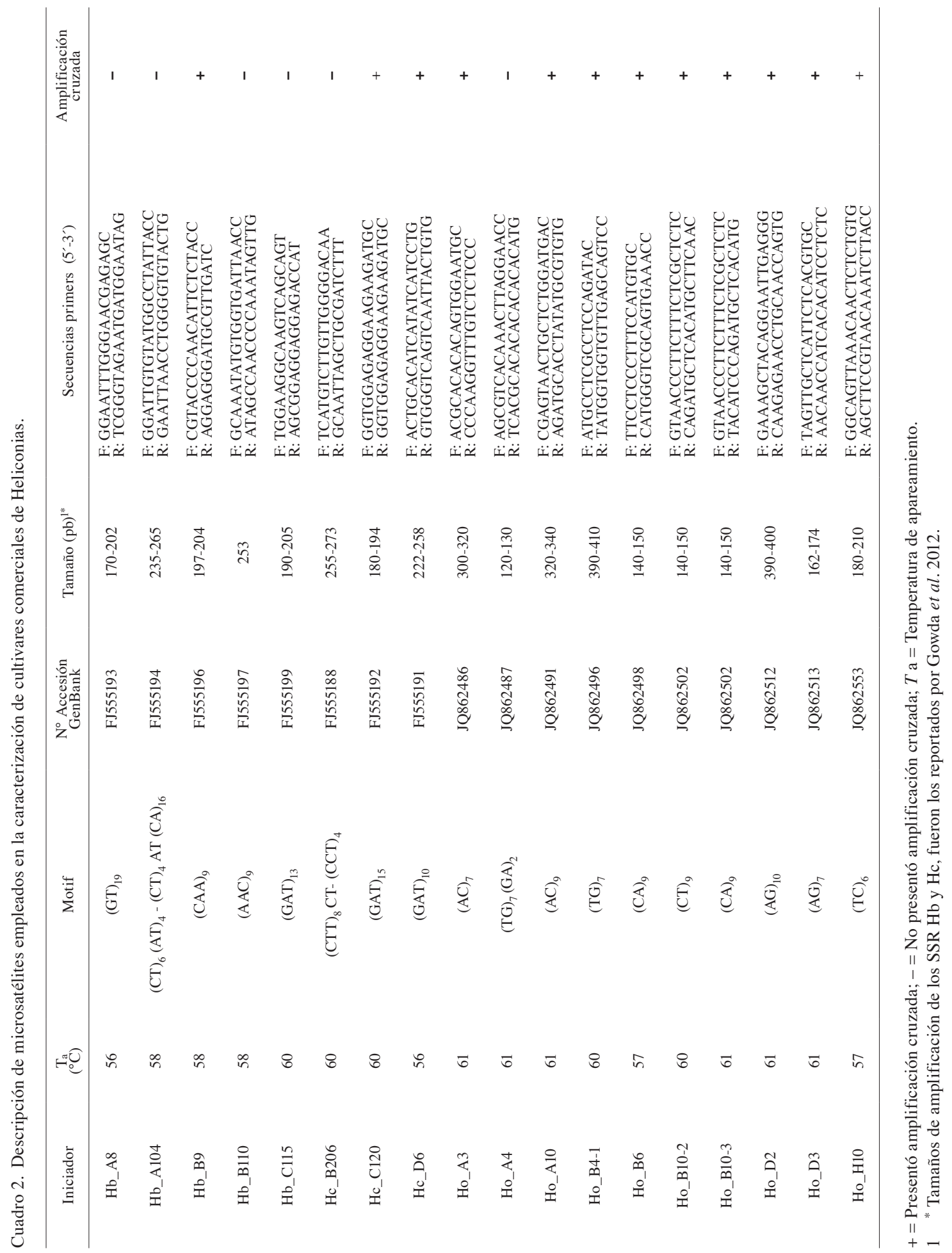

Agronomía Costarricense 42(1): 7-20. ISSN:0377-9424 / 2018 
Análisis Estadístico: Se realizó un análisis inicial por medio del programa GenAlex 6,1 (Peakell y Smouse 2006) al estimar las medidas de diversidad, variabilidad y distancias genéticas. Se generó una matriz binaria de ausencia (0) y presencia (1). Se halló la matriz de similitud al calcular el coeficiente de Nei (1972), para estimar los parámetros de heterocigosidad promedio. A partir de la matriz de distancias, se construyó un dendrograma con Bootstrap con el software MEGA7 (Molecular Evolutionary Genetics Analysis v 7.0, desarrollado por Kumar et al. (2015)).

También se calcularon los índices de contenido polimórfico (PIC) a través de la aplicación PIC calculator. Los datos de heterocigosidades esperadas y observadas, además de los valores de PIC, se utilizaron para seleccionar parejas de primers que sirvieran en la discriminación genética de cultivares de heliconias. La heterocigosidad observada y esperada, el equilibrio de Hardy Weinberg (EHW) por la prueba exacta, el desequilibrio de ligamiento (LD) y el estadístico $\mathrm{F}_{\mathrm{ST}}$ por cada locus, fueron estimados mediante el software Arlequin v 3.5 (Excoffier et al. (2010)) el cual usa el método de Cadena de Markov.

\section{RESULTADOS Y DISCUSIÓN}

Para la presente investigación, la amplificación de las muestras de cultivares comerciales de heliconias con marcadores microsatélites, reveló que cada pareja de iniciadores amplificó en su mayoría un locus, entre tanto, los microsatélites
Hb_C115, Hc_C120 y Ho_A3 presentaron 2 loci. Al comparar las frecuencias alélicas de cada uno de los loci en cada población (especies diferentes), se observaron microsatélites multialélicos, donde el locus Ho_H10 aportó el mayor número de alelos, 15 de los 152 alelos totales registrados en 21 loci. Otros estudios, como el de Cortes et al. (2009), caracterizaron con 10 loci microsatélites la especie Heliconia acuminata colectada en el proyecto "Biological Dynamics of Forest Fragments Project (Manaus, Brazil)". Los marcadores se utilizaron para analizar 61 individuos pertenecientes a una población en estudio, estos marcadores fueron muy polimórficos con un promedio de 8 alelos por locus. Todos los marcadores son utilizados actualmente para analizar la estructura genética y espacial de la población, y para comprender la dinámica sucesional de la especie $H$. acuminata en fragmentos de bosque tropical.

En la Figura 2 se observa la distribución de los diferentes alelos detectados en los 21 loci microsatélites, pertenecientes a las 4 especies y a los híbridos interespecíficos de heliconias. La heterocigosidad esperada (He) fue mayor en $H$. bihai $(0,674)$, seguida de H. stricta $(0,672)$ (Figura 2). También se observó que $H$. bihai presentó el mayor número de alelos exclusivos $(0,762)$, seguida de $H$. stricta $(0,429)$, en contraste $H$. caribaea registró el menor número de alelos $(0,048)$. La presencia de ellos con frecuencias iguales o inferiores al 50\% (alelos de baja frecuencia) se presentó en mayor número en $H$. bihai y $H$. stricta, de igual forma ambas especies registraron el mayor número de alelos frecuentes y los informativos. 


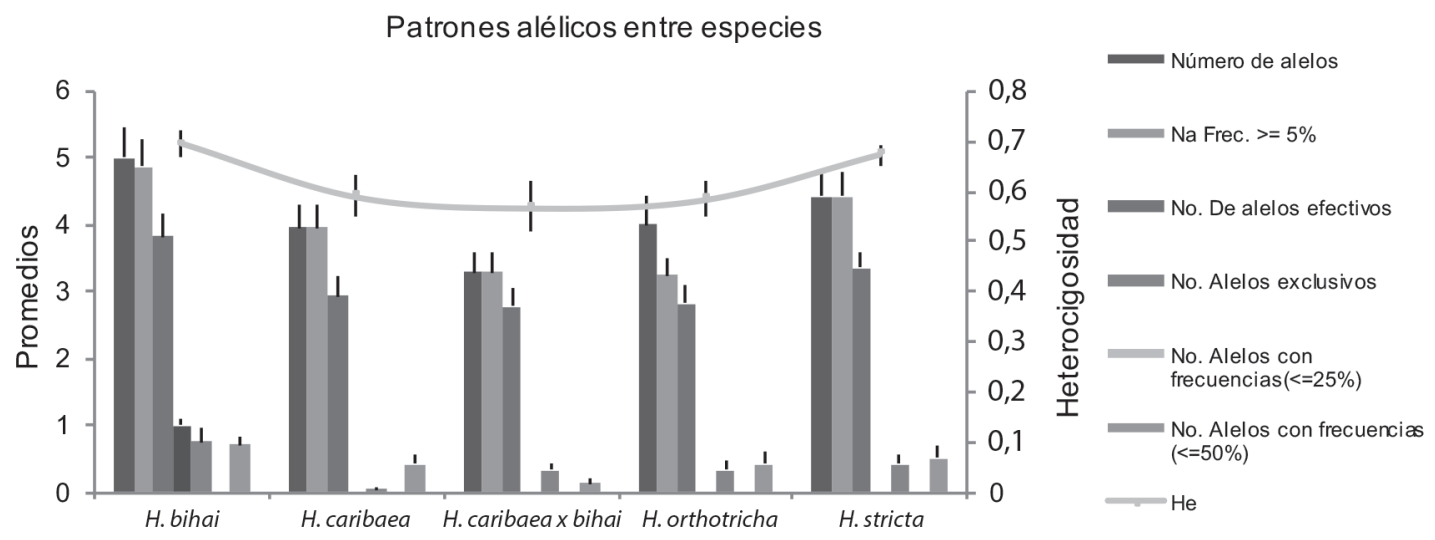

Especies

Fig. 2. Distribución de los patrones alélicos en muestras de heliconias. He: Heterocigosidad esperada.

Pereira et al. (2016), caracterizaron 15 familias de medios hermanos de cultivos de heliconias en Brasil, mediante marcadores morfológicos y moleculares. Para la media familia de muestras de $H$. bihai, el valor de heterocigosidad esperada (He) fue de 0,242 , catalogada como alta diversidad. Este valor es inferior al hallado en el presente estudio y podría ser explicado en que las muestras colombianas no eran emparentadas, aunque sí son cultivares comerciales seleccionados por agricultores.

La estrategia de utilizar los principios de transferibilidad de los marcadores microsatélites en especies del mismo género aportaron resultados muy positivos en esta investigación (Cuadro 3), pues se observa que SSR desarrollados para Heliconia orthotricha (Primers Ho) pueden hacer una diferenciación intraespecífica en cultivares de las especies $H$. bihai, $H$. caribaea y H. stricta. Jatoi et al. (2006) analizaron la diversidad genética mediante el uso de marcadores microsatélites (SSR) o secuencias simples repetidas de 14 genotipos de 3 géneros de la familia Zingiberaceae (Zingiber, Alpinia y Curcuma), los cuales mostraron una gran diversidad en hábitat y morfología, pero es poco el conocimiento acerca de las relaciones filogenéticas entre estos taxones, debido a la falta de marcadores moleculares propios. Estos investigadores utilizaron marcadores microsatélites y evaluaron el potencial de amplificación cruzada de secuencias microsatélites (SSR) entre diferentes taxones con el fin de identificar marcadores genéticos para caracterizar la diversidad genética del orden. Se utilizaron, además, marcadores microsatélites (SSR) de arroz en especies de Zingiberaceae, lo cual demostró la transferibilidad de los microsatélites entre grupos aparentemente no muy relacionados. Según Mathithumilan et al. (2013), evolutivamente, las especies pertenecientes a un género o familia específica tienen cierta relación a nivel genómico. Por lo tanto, es plausible que los marcadores sean transferibles a través de estas especies pertenecientes a la misma familia. Además, es evidente que las regiones codificantes son más conservadas a través de los phylum que las partes no codificantes del genoma. 
Cuadro 3. Selección de microsatélites para discriminación de cultivares del género Heliconia.

\begin{tabular}{|c|c|c|c|c|c|}
\hline $\begin{array}{l}\text { Especie } \\
\text { Locus }\end{array}$ & H. bihai & H. caribaea & $\begin{array}{c}\text { H. caribaea } \mathrm{x} \\
\text { H. bihai }\end{array}$ & H. orthotricha & H. stricta \\
\hline Hb_C115 & $* * *$ & $*$ & $*$ & $*$ & $*$ \\
\hline Hb_B9 & $*$ & $*$ & $* * *$ & $*$ & $*$ \\
\hline Hc_B206 & $* *$ & $*$ & $*$ & $* *$ & $*$ \\
\hline Hc_C120 & $*$ & $* *$ & $* *$ & $* * *$ & * \\
\hline Hc_B6 & $* *$ & $*$ & $*$ & $*$ & $* * *$ \\
\hline Ho_A3 & $*$ & $*$ & $*$ & $*$ & $* * *$ \\
\hline Ho_A4 & $* * *$ & $*$ & * & $*$ & * \\
\hline Ho_A10 & $* *$ & $*$ & * & $* *$ & * \\
\hline Ho_B4-1 & $*$ & $*$ & * & $* * *$ & $*$ \\
\hline Ho_B6 & $*$ & $*$ & $*$ & $*$ & $* *$ \\
\hline Ho_B10-2 & $* * *$ & $*$ & * & $*$ & $*$ \\
\hline Ho_D2 & $* * *$ & $*$ & * & $*$ & * \\
\hline Ho_D3 & $*$ & $* * *$ & $*$ & $*$ & $*$ \\
\hline Ho_H10 & $*$ & $*$ & $*$ & $*$ & $* *$ \\
\hline
\end{tabular}

*No es informativo**Diferenciación interespecífica ***Diferenciación intraespecífica.

Con el fin de discriminar cultivares entre sí, se analizó el número de concordancias versus genotipos por locus, para determinar la probabilidad de encontrar 2 individuos con el mismo genotipo en un determinado locus. Se encontró que era necesaria la utilización de más de 16 loci para distinguir cultivares de diferentes especies. Los resultados donde se utilizan marcadores moleculares para distinguir individuos son reportados también por Pereira et al. (2016), quienes con marcadores moleculares ISSR (Por sus siglas en inglés: Inter Simple Sequence Repeats) distinguieron individuos emparentados de $H$. bihai y H. chartacea. Por su parte, Gowda et al. (2012) desarrollaron 13 marcadores microsatélites para la caracterización de $H$. caribaea y $H$. bihai en islas orientales caribeñas, lo cual demostró un alto poder de discriminación en la caracterización genética de estas especies que comprobó, además, la utilidad de los microsatélites para estudios de polinización, estructura genética y patrones filogeográficos en heliconias del caribe.
La mayor variabilidad de los microsatélites, en comparación con otros marcadores, aumenta la probabilidad de que cada individuo en una población, tenga un genotipo único, lo cual hace que los microsatélites sean muy útiles en caracterizaciones genéticas a nivel poblacional (Slatkin 1995, Marulanda et al. 2011). Se tiene en cuenta la necesidad de recomendar 16 loci para distinguir cultivares; se seleccionaron 14 microsatélites, ya que 3 de los 18 microsatélites analizados mostraron 2 loci. Los SSR con un mayor contenido polimórfico (PIC), heterocigosidades observadas y esperadas similares fueron: Hb_C115, Hb_B9, Hc_B6, Hc_C120, Ho_A3, Ho_A4, Ho_B4-1, Ho_B10-2, Ho_D2 y Ho_D3. En el Cuadro 3, aparecen las capacidades de diferenciación intra y / o interespecífica de los SSR seleccionados.

El análisis de equilibrio de Hardy-Weinberg (EHW) fue desarrollado por cada locus en cada cultivar al tomar todas las muestras como un solo grupo. Los resultados de la tabla con los P-valores para cada caso se presentan en 
el Cuadro 4, donde los valores menores a 0,05 $(\mathrm{p}<0,05)$ fueron significativos, lo cual indica que se rompió el equilibrio de Hardy-Weinberg para ese marcador. El cultivar con más marcadores en desequilibrio fue $H$. orthotricha y el de menos $H$. caribaea $x$ bihai. Además, cuando se unen todos los cultivares hay más marcadores en desequilibrio porque se juntan grupos diferentes entre sí. A diferencia de Cortes et al. (2009), quienes analizaron la estructura genética y espacial de una población $H$. acuminata en fragmentos de bosque tropical en Manaus, Brasil. Las muestras evaluadas en el presente estudio, son de cultivares comerciales con alta presión de selección por parte de los cultivadores, es de esperarse entonces, que se rompa el equilibrio Hardy-Weinberg (EHW) para algunos de los marcadores empleados en las diferentes especies. Liew et al. (2016) encontraron una desviación significativa del equilibrio de Hardy-Weinberg (EHW) al realizar una amplificación cruzada con microsatélites de la especie Duabanga molucca$n a$ en otras especies relacionadas; ellos explican este fenómeno, debido al déficit de heterocigotos y a la presencia de alelos nulos (Selkoe y Toonen 2006). Además, contemplaron que el exceso de homocigotos puede deberse a las condiciones propias de la población a estudiar, como la endogamia, la selección en contra o favor de cierto alelo, entre otros. Cabe resaltar que la población analizada en este estudio es producto de una alta presión de selección, al ser cultivares seleccionados para explotación comercial y posteriormente propagados asexualmente.

Cuadro 4. P-valores para el equilibrio de Hardy-Weinberg (EHW) en cada cultivar y en el grupo completo.

\begin{tabular}{|c|c|c|c|c|c|c|}
\hline Locus* & H. bihai & H. caribaea & $\begin{array}{l}\text { H. caribaea } x \\
\text { H. bihai }\end{array}$ & H. orthotricha & H. stricta & $\begin{array}{l}\text { Población } \\
\text { Total }\end{array}$ \\
\hline Hb_A8 L1 & 0,016 & 0,418 & 1,000 & 0,003 & 0,004 & 0,000 \\
\hline Hb_A104 L1 & 0,014 & 0,005 & 1,000 & 1,000 & 0,013 & 0,000 \\
\hline Hb_B9 L1 & 0,875 & 0,775 & 1,000 & 1,000 & 0,642 & 0,118 \\
\hline Hb_B110 L1 & 0,304 & 0,060 & 0,312 & 0,015 & 0,269 & 0,000 \\
\hline Hb_C115 L1 & 0,386 & 1,000 & 0,400 & 0,093 & 0,072 & 0,000 \\
\hline Hb_C115 L2 & 1,000 & 1,000 & Monomórfico & 1,000 & 1,000 & 0,101 \\
\hline Hc_B206 L1 & 0,576 & 0,060 & 0,323 & 0,117 & 0,255 & 0,030 \\
\hline Hc_C120 L1 & 0,049 & 0,059 & 0,314 & 0,120 & 0,025 & 0,000 \\
\hline Hc_C120 L2 & 0,399 & 1,000 & 1,000 & 1,000 & 1,000 & 0,063 \\
\hline Hc_D6 L1 & 0,167 & 0,006 & 1,000 & 1,000 & 0,023 & 0,000 \\
\hline Ho_A3 L1 & 0,001 & 0,025 & 0,055 & 0,001 & 0,041 & 0,000 \\
\hline Ho_A3 L2 & 1,000 & 1,000 & Monomórfico & 1,000 & 0,250 & 0,076 \\
\hline Ho_A4 L1 & 0,075 & 0,092 & 0,059 & 0,007 & 0,063 & 0,000 \\
\hline Ho_A10 L1 & 0,092 & 0,380 & 0,314 & 0,284 & 0,423 & 0,021 \\
\hline Ho_B4-1 L1 & 0,002 & 1,000 & 1,000 & 0,843 & 0,001 & 0,000 \\
\hline HoB6 L1 & 0,014 & 0,053 & 1,000 & 0,007 & 0,208 & 0,000 \\
\hline Ho_B10-2 L1 & 0,104 & 0,848 & 1,000 & 0,235 & 0,110 & 0,066 \\
\hline Ho_B10-3 L1 & 0,433 & 1,000 & 0,467 & 0,033 & 0,152 & 0,000 \\
\hline Ho_D2 L1 & 0,975 & 0,156 & 0,659 & 0,104 & 0,861 & 0,000 \\
\hline Ho_D3 L1 & 0,531 & 0,000 & 1,000 & 0,015 & 0,338 & 0,000 \\
\hline Ho_H10 L1 & 0,445 & 0,424 & 1,000 & 0,789 & 0,295 & 0,009 \\
\hline Significativos & 6 & 4 & 0 & 7 & 6 & 16 \\
\hline
\end{tabular}

$* \mathrm{~L} 1=$ Locus $1 . \mathrm{L} 2=$ Locus 2 
Por otro lado, se estimó el desequilibrio de ligamiento (LD) por pares de locus, se tomaron todos los individuos como una única población, a partir de estos se determinó la significancia del ligamiento, donde se puede observar que el marcador Hb_C115 presentó el ligamiento con un mayor número de marcadores, lo cual podría ofrecer información redundante de ellos. Cabe aclarar que aunque muchos de los marcadores están ligados entre sí, al no poseer mapas de ligamiento para ninguna especie del género, no es posible determinar la cercanía de los mismos en los cromosomas.

El análisis de los $\mathrm{F}_{\mathrm{ST}}$ se realizó con el fin de identificar posibles marcadores bajo selección y se tuvo en cuenta todos los cultivares como un grupo global. En este caso solo 2 marcadores fueron significativos $(\mathrm{p}$-valor $<0,05)$ con valores de $\mathrm{F}_{\mathrm{ST}}$ de 0,333 y de 0,171 para los locus Hb_C115 y Hc_C120, lo que indica que estos 2 marcadores muestran estructuración poblacional.

En la Figura 3 se observan 7 grupos bien definidos, no existe una tendencia clara de los individuos a agruparse por especie con los microsatélites utilizados en este estudio, aunque
6 individuos de la especie $H$. orthotricha se encuentran en el primer grupo, lo cual confirma la especificidad de los microsatélites desarrollados para esta especie. En general, la cercanía de las especies utilizadas en esta investigación radica básicamente en que todas pertenecen al subgénero Heliconia sección Heliconias: $H$. bihai (L.) L. H. orthotricha L. Andersson, $H$. stricta Huber, $H$. caribaea Lamarck y $H$. wagneriana Peterssen (no incluida en este estudio) (Kress et al. 1999). Esta clasificación se basa principalmente en las características vegetativas y reproductivas de las plantas. Las especies que pertenecen a la sección Heliconia presentan pseudotallos más largos e inflorescencias erectas y con espatas no muy imbrincadas (Betancur y Kress 1995). Los estudios filogenéticos de las especies pertenecientes a la sección Heliconia demuestran la existencia de un ancestro común y ha sido descrita como una sección cuyo origen evolutivo es monofilético (Marouelli et al. 2010). Es preciso mencionar, además, que es muy común en las especies de heliconias tanto en cultivadas como silvestres, encontrar híbridos naturales interespecíficos. 


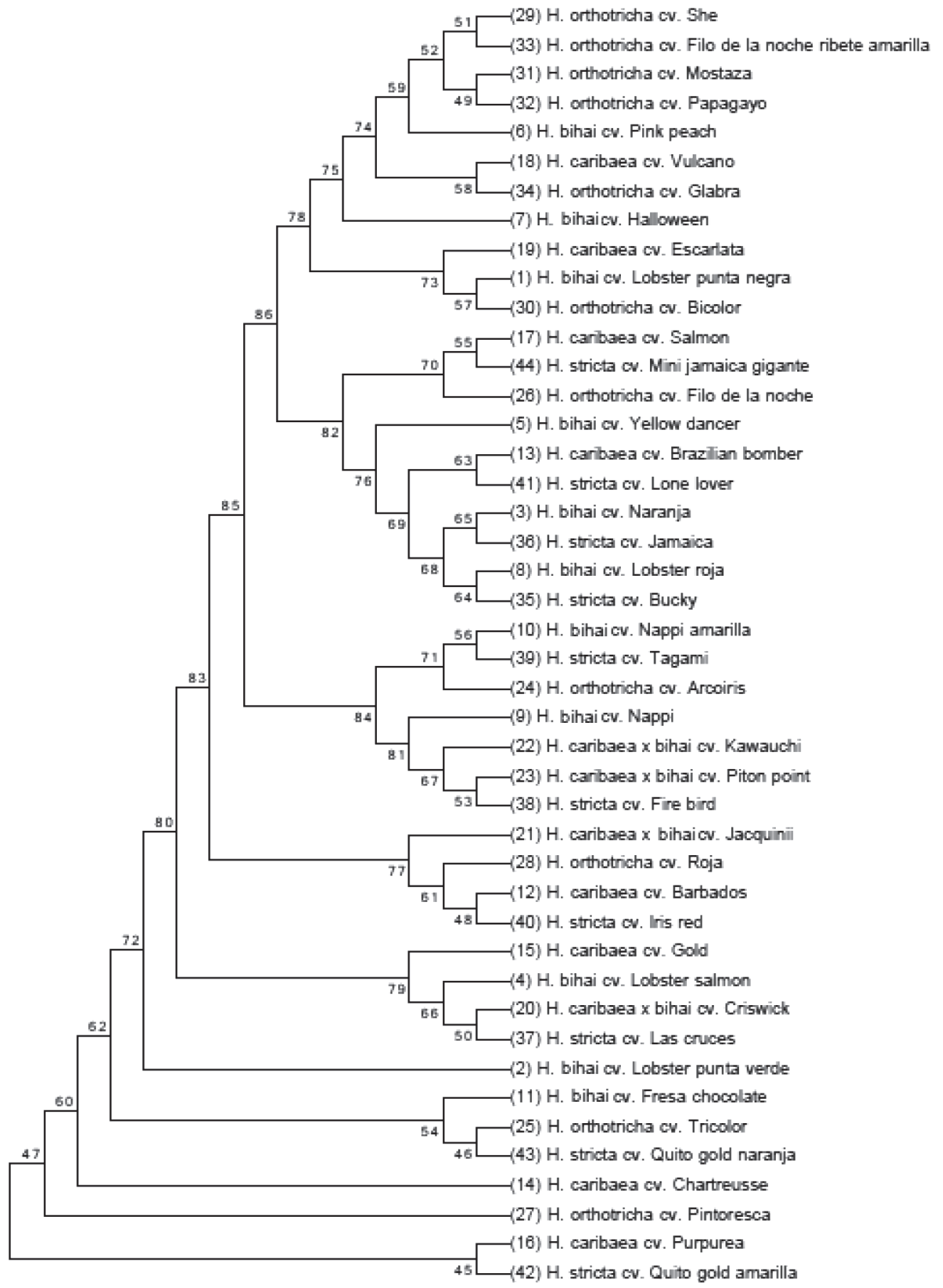

Fig. 3. Dendrograma obtenido con coeficiente de Jaccard y agrupamiento Neighbor-Joining con bootstrap, en diferentes genotipos de cultivares comerciales del género Heliconia. 
Finalmente, es importante destacar que el uso de las técnicas moleculares permite la estimación de la diversidad genética dentro y entre especies, para estudios poblacionales, clasificación de germoplasma, mejoramiento e identificación de genes de caracteres cualitativos y cuantitativos mediante la identificación del polimorfismo directamente del ADN (Cornide 2000).

\section{CONCLUSIONES}

Se logró determinar que la utilización de más de 16 loci fue útil para distinguir cultivares de diferentes especies. Se tiene en cuenta, la necesidad de recomendar 16 loci para distinguir cultivares, se seleccionaron 14 microsatélites, ya que 3 de los 18 microsatélites analizados mostraron 2 loci.

Este estudio confirma la transferibilidad de los microsatélites desarrollados para diferentes especies del género Heliconia, como una herramienta útil en la caracterización varietal, la cual podría ser de gran uso en la comercialización de flores e intercambio de material vegetal para propagación asexual.

\section{AGRADECIMIENTOS}

Los autores expresan sus agradecimientos a COLCIENCIAS mediante su programa Jóvenes investigadores e Innovadores "Virginia Gutiérrez de Pineda", a las Universidades Tecnológica de Pereira (Colombia) y Estatal de Campinas (Brasil) y al Sistema General de Regalías (Departamento Nacional de Planeación), por financiar el Programa de investigación "Desarrollo de capacidades científicas y tecnológicas en biotecnología aplicada a los sectores de la salud y la agroindustria en el departamento de Risaralda", identificado con código BPIN 2012000100050.

\section{LITERATURA CITADA}

Andersson, L. 1998. Heliconiaceae. In Kubitzki, K (ed.). The Families and Genera of Vascular Plants. IV. Flowering Plants. Monocotyledons. Alismatanae and Commelinanae (except Gramineae). Springer, Berlin. p. 226-230.

Benbouza, H; Jacquemin JM; Baudoin JP; Mergeai, G. 2006. Optimization of a reliable, fast, cheap and sensitive silver staining method to detect SSR markers in polyacrylamide gels. Biotechnologie, Agronomie, Société et Environnement 10(2):77-81.

Berry, F; Kress, WJ. 1991. Heliconia: An Identification Guide. Smithsonian Institution Press, Washington. USA. 334 p.

Betancur, J; kress, W. 1995. Distribución geográfica y altitudinal del género Heliconia (Heliconiaceae en Colombia). In Churchill SP; Balslev, H; Forero, E; Luteyn, JL (eds.). Biodiversity and Conservation of Neotropical Montane Forests. The New York Botanical Garden, New York, USA. p. 513-523.

Castillo, NR. 2006. Fingerprinting and genetic stability of Rubus using molecular markers. Thesis M. Sc. Oregon, USA, Oregon State University. 244 p.

Castro, CEF; Gonçalves, C; May, A. 2007. Heliconia species as cut flower. Rev. Bras. Hortic. Ornam. 12:87-96.

Cornide, M. 2000. Diversidad genética y marcadores moleculares. Departamento de Bioplantas, CNIC. La Habana, Cuba. 150 p.

Cortes, SM; Gowda, V; Kress, J; Bruna, E; Uriarte, M. 2009. Characterization of 10 microsatellite markers for the understorey Amazonian herb Heliconia acuminata. Molecular Ecology Resources 9(4):1261-1264.

Costa, AS; Loges, V; Castro, ACR; Guimarães, WNR. 2009. Heliconia genotypes under partial shade: II. Evaluation of flowering stems. Acta Hort. 813:171-176.

Excoffier, L; Lischer, HE . 2010. Arlequin suite ver 3.5: A new series of programs to perform population genetics analyses under Linux and Windows. Molecular Ecology Resources 10:564-567.

Gowda, V; Erickson, DL; Kress, WJ. 2012. Development and characterization of microsatellite loci for two Caribbean Heliconia (Heliconiaceae: H. bihai and $H$. caribaea). American Journal of Botany 99(2):e81-e83.

Guimarães, WNR; Martins, LSS; Castro, CEF; Carvalho, FJ; Loges, V. 2014. Heliconia phenotypic diversity based on qualitative descriptors (en línea). Genetics and Molecular Research 13(2):3128-3142. Consultado 17 sep. 2016. Disponible en http://dx.doi. org/10.4238/2014.April.17.9

Jatoi, A; Kikuchi, A; Yi, S; Naing, K; Yamanaka, S; Watanabe, A. 2006. Use of rice SSR markers as RAPD markers for genetic diversity analysis in Zingiberaceae. Breeding Science 56:107-111.

Kress, J; Betancur, J; Echeverry, B. 1999. Heliconias: llamaradas de la selva colombiana. Santafé de Bogotá, Colombia. HortiTecnia. 191 p. 
Kumar, S; Stecher, G; Tamura, K. 2015. MEGA7. Molecular Evolutionary Genetics Analysis (en línea, programa informático) version 7.0. Molecular Biology and Evolution (submitted). Consultado 02 oct. 2017. Disponible en http://www.kumarlab.net/ publications

Liew, K; Ho, W; Pang, S; Abdullah, J. 2016. Development, Polymorphism and Cross-Species Transferability of Genomic SSR Markers in Duabanga Moluccana, an Indigenous Tree Species from Sarawak. OnLine Journal of Biological Sciences 16(1):57-70.

Loges, V; Castro, ACR; Costa, AS; Verona, AL; Nogueira, LC; Guimarães, WNR; Castro, MFA; Bezerra, M. 2007. The ornamental attributes of heliconia for landscape design in Brazil (en línea). Acta Hortic. 743, 75-80. Consultado 15 may. 2016. Disponible en https://doi.org/10.17660/ActaHortic.2007.743.9

Marouelli, P; Inglis, PW; Ferreira; MA; Buso, GSC. 2010. Genetic relationships among Heliconia (Heliconiaceae) species based on RAPD markers. Genetics and Molecular Research 9(3):1377-1387.

Marulanda, M; Isaza, L; Duque, A; Londoño, L. 2011. Biodiversidad y biotecnología en la evaluación de cultivares comerciales de heliconias. Risaralda, Colombia. 123 p.

Mathithumilan, B; Kadam, NN; Biradar, J; Sowmya, H; Mahadeva, A; Madhura, JN. 2013. Development and characterization of microsatellite markers for Morus spp. and assessment of their transferability to other closely related species. BMC Plant Biol. 13:194-215.

Nei, M. 1972. Genetic distance between populations American Naturalist 106(949):283-392.

Peakall, R; Smouse, PE. 2006. GENALEX 6: genetic analysis in Excel. Population genetic software for teaching and research. Mol. Ecol. Notes 6:288-295.

Pereira, FRA; Moraes, RM; Filho, LSS; Martins, AVV; Montarroyos; Loges, V. 2016. Genetic diversity and morphological characterization of half-sib families of Heliconia bihai L., H. chartacea Lane ex Barreiros, and $H$. wagneriana Peterson. Genetics and Molecular Research 15(2):1-9.

Selkoe, KA; Toonen, RJ. 2006. Microsatellites for ecologists: A practical guide to using and evaluating microsatellite markers. Ecol. Lett. 9:615-629.

Sheela, L; Geetha, P; Jayachandran, C; Rajmohan, K. 2006. Molecular characterization of Heliconia by RAPD assay. Journal of Tropical Agriculture 44:37-41.

Slatkin,M. 1995. A measure of population subdivision based on microsatellite allele frequencies. Genetics 139:457462.

UN Comtrade Database (United Nations Common Format For Transient Data Exchange for power systems). 1962-2017. (en línea). Consultado 08 ene. 2017. Disponible en http://atlas.media.mit.edu/es/profile/ hs92/0603! 